\title{
A safety study of laparoscopic single-anastomosis duodeno-ileal bypass with gastric plication (SADI-GP) in the management of morbid obesity
}

\author{
Istvan Bence Balint ${ }^{1}$ • Ferenc Csaszar ${ }^{2,3}$ - Lajos Orban ${ }^{4} \cdot$ Peter Radics $^{5} \cdot$ Akos Farics $^{4} \cdot$ Gergo Manfai $^{4} \cdot$ Veronika Hari $^{6}$. \\ Rebeka Javor ${ }^{7}$
}

Received: 21 April 2021 / Accepted: 13 July 2021 / Published online: 17 August 2021

(c) The Author(s) 2021

\begin{abstract}
Background Bariatric surgery is more effective in the management of morbid obesity and related comorbidities than is conservative therapy. Pylorus-preserving single-anastomosis duodeno-ileal bypass with sleeve gastrectomy (SADI-SG) is a modified duodenal switch technique. Gastric plication (GP) is an alternate to SG.

Methods Morbidly obese (BMI of $>40$, or $>35$ in the presence of diabetes or prediabetes) patients were recruited and operated on to perform SADI with GP. Complications related to surgery were recorded to assess the feasibility of the procedure. Weight-loss outcomes were analysed to determine efficacy. Minnesota Multiphasic Personality Inventory 2 (MMPI-2) was recorded after 1 year of follow-up, and test scales were used to describe physiological phenomena.

Results Seventeen middle-aged (mean: 40 years) patients were involved in our study; 15 of them were females. The mean duration of surgery was $205 \mathrm{~min}$. There were no complications of conversion, death, bleeding, VTE or 30-day readmission to hospital. We did experience CD4a (pulmonary insufficiency due to chronic lung disease) and a CD3b (anastomosis leakage treated laparoscopically) complications. Vomiting occurred in three cases (CD1). Obesity-related comorbidities showed favourable resolution rates (77.8\% for hypertension, $81.2 \%$ for dyslipidaemia, $100 \%$ for diabetes at the 1-year follow-up). Weight-loss outcomes were favourable (53.20 EWL\%, and 35.58 TWL\% at 1-year follow-up). Greater weight loss caused significantly higher levels of Depression $(t(13.958)=-2.373 ; p=0.00 ; p<0.05)$ and Low Positive Emotions $(t(13.301)=-2.954 ; p=0.00$; $p<0.05)$ and Introversion/Low Positive Emotionality $(t(13.408)=-1.914 ; p=0.02 ; p<0.05)$ in MMPI-2 data.

Conclusion According to our safety study, SADI-GP is a promising malabsorptive procedure, but a long-term high-volume case series or a randomised controlled trial is necessary to evaluate complication rates and weight-loss outcomes. Emotional dysregulation is common among bariatric surgery patients according to personality inventory data; therefore, psychological follow-up and psychotherapeutic support are necessary for weight-loss maintenance.
\end{abstract}

Keywords Bariatric surgery $\cdot$ Metabolic surgery $\cdot$ Single-anastomosis duodeno-ileal bypass $\cdot$ One-anastomosis duodenoileal bypass - Omega-loop duodeno-ileal bypass · Gastric plication · Greater curvature plication · Minnesota Multiphasic Personality Inventory $2 \cdot$ Psychological evaluation · Obesity

\begin{tabular}{llll}
\multicolumn{2}{l}{ Abbreviations } & DS & Duodenal switch \\
ANOVA & Analysis of variances & EWL\% & Percentage excess weight loss \\
BMI & Body mass index & GERD & Gastroesophageal reflux disease \\
BMR & Basal metabolic rate & HgbA1C\% & Haemoglobin A1C in percent \\
BPD & Biliopancreatic diversion & ICU & Intensive Care Unit \\
CD & Clavien-Dindo classification & LAGB & Laparoscopic adjustable gastric banding \\
CI & LGP & Laparoscopic gastric plication \\
& Confidence interval & LRGB & Laparoscopic Roux-en-Y gastric bypass \\
& LSG & Laparoscopic sleeve gastrectomy \\
Istvan Bence Balint & NAFLD & Non-alcoholic fatty liver disease \\
\multicolumn{2}{rl}{ balint.istvan.bence@gmail.com; } \\
balint_istvan_bence@yahoo.com & OAGB & One-anastomosis gastric bypass \\
Extended author information available on the last page of the article & OSA & Obstructive sleep apnoea
\end{tabular}




\begin{tabular}{|c|c|}
\hline $\mathrm{PCO}$ & Polycystic ovarian syndrome \\
\hline PF-CBT & $\begin{array}{l}\text { Problem-focused cognitive behavioural } \\
\text { therapy }\end{array}$ \\
\hline PPI & Proton pump inhibitor \\
\hline QoL & Quality of life \\
\hline RCT & Randomised controlled trial \\
\hline SADI-SG & $\begin{array}{l}\text { Single-anastomosis duodeno-ileal bypass } \\
\text { with sleeve gastrectomy }\end{array}$ \\
\hline SADJ-SG & $\begin{array}{l}\text { Single-anastomosis duodeno-jejunal bypass } \\
\text { with sleeve gastrectomy }\end{array}$ \\
\hline SD & Standard deviation \\
\hline $\mathrm{T} 2 \mathrm{DM}$ & Type 2 diabetes mellitus \\
\hline TWL\% & Percentage total weight loss \\
\hline VTE & Venous thromboembolism \\
\hline
\end{tabular}

\section{Introduction}

\section{Background}

Morbid obesity is in correlation with hypertension, dyslipidaemia, prediabetes and T2DM [1]. If lifestyle modifications failed, bariatric surgery would be advised to morbidly obese patients [2-8]. LAGB, LSG and LGP are restrictive procedures [2-24]. BPD, SADJ-SG or SADI-SG, LRYGB and OAGB are malabsorptive surgical techniques [25-42]. LGP combined with omega-loop duodenal switch was described by Karcz et al. [43]. An experimental model described the superiority of SADJ-GP over SG in terms of efficacy in the remission of T2DM [44]. Two prospective observational studies reporting outcomes of a combination of LGP and OAGB were identified during a literature search $[45,46]$.

SADJ-SG and SADI-SG seem to have advantages over gastric bypass procedures (LRYGB and OAGB) because a more physiologic anastomosis (duodeno-jejunal or -ileal) is performed. Therefore, anastomotic ulcers deriving from afferent limb bile reflux through gastro-jejunal anastomosis should occur less frequently [27-35]. SG is the first part of these procedures which is very popular among bariatric surgeons due to its simplicity; however, it is only a restrictive method without the advantages of exclusion duodenojejunal mucosa from digestion. The major concerns of LSG are bleeding, leakage and augmented symptoms of GERD after surgery [2-7, 15, 19, 20, 22, 24]. During LGP, greater curvature of the stomach is invaginated into the gastric lumen in two or three folds by two layers of laparoscopic interrupted or running sutures. Gastric release, dilatation and prolapse (probably synonyms of the same effect in different stages) are common complications after LGP instead of bleeding and leakage. Gastric necrosis or perforation occurs rarely. Nausea and vomiting are associated with LGP very frequently [10-24].

\section{Objective}

This paper presents the short-term results of the LASAGNE trial (LAparoscopic Single- $\underline{\text { Anastomosis duodeno- }}$ ileal bypass with Gastric plication (SADI-GP) in the maNagEment of morbid obesity) registered under number ISRCTN12800723 and approved by the institutional review board of Kanizsai Dorottya Hospital (hospital of Nagykanizsa) under protocol number KDK-2071-2/2019. The study is aimed to assess the safety and efficacy of SADI-GP based on a prospective cohort of patients recruited consecutively. We believe that combining well researched SADI with GP instead of SG could result in better complication rates and plausible metabolic outcomes.

\section{Methods}

\section{Study design and setting}

This trial used a cohort of consecutively admitted patients aiming at the assessment of complication rates and efficacy of SADI-GP. Patient recruitment began in October 2018 and ended in June 2019 (the last operation was performed in November 2019). Preoperative evaluation followed by surgery and postoperative follow-up visits (at 1, 3, 6 and 12 months) were planned.

\section{Participants}

Patients between 18 and 65 years, with BMIs of $>40$ (without comorbidity related to morbid obesity) or $>35$ (with comorbidity related to morbid obesity, especially glucose metabolism) were included. Patients who had previous bariatric surgery, who had severe mental disorders (drug addiction, alcohol consumption, the use of antipsychotics), who were regarded as socially vulnerable patients, who were completely immobile, who were unable to understand the purpose of the study and bariatric surgery, who denied or withdrew their informed consent, for whom duodeno-ileal bypass was not performed during surgery or who dropped out before the 6-month follow-up were excluded.

\section{Variables}

Primary endpoints of the study were to assess the safety of the investigated method and evaluate the risks due to surgery. Secondarily, weight-loss outcomes were analysed. 


\section{Data source}

The previous history, including the presence of hypertension, prediabetes, T2DM, dyslipidaemia, gout, cardiovascular disease, pulmonary disease, chronic venous disorder, PCO, OSA, GERD, peptic ulcer, osteoarthritis and mental disorders, was obtained. Body weight, height, BMI adjusted for age-gender-ethnicity, ideal weight (BMI of 25), excess weight and excess BMI were measured. Preoperative examinations (transthoracal cardiac ultrasound, abdominal ultrasound, carotid duplex ultrasound, spirometry, oesophagogastro-duodenoscopy) were carried out. Blood tests (blood count, ionogram, serum protein, glucose, $\mathrm{HgbA1C} \%$, ironbinding capacity, lipid profile, kidney and liver function and haemostasis) were planned at baseline and at each followup visit. QoL was measured by BAROS-Moorehead-Ardelt II and Weiner et al. questionnaires [47, 48]. Postoperative complications were classified by Clavien-Dindo [49, 50].

\section{Procedure}

Patients were operated in French position. The operating surgeon was positioned between the patient's legs and one assistant surgeon was placed on each side. Under combined (general and peridural) anaesthesia, a skin incision was made one span $(15-20 \mathrm{~cm})$ under the xiphoid process, then the abdominal wall was prepared and lifted directly to prepare carbon dioxide peritoneum with a Veres needle, and an optic trocar $(15 \mathrm{~mm})$ was placed into the intra-abdominal cavity. Under visualisation, ports were created left $(5-10 \mathrm{~mm})$ and right (5-12 $\mathrm{mm}$ ) of the umbilicus in the mid-clavicular line under the xiphoid process (10-12 $\mathrm{mm}$ depending on the type of liver retractor) and under the left rib arc in the front axillary line $(5 \mathrm{~mm})$. A liver retractor was placed through the epigastrial port, and the left upper abdomen was explored. The gastrocolic and gastrolienal ligaments were dissected besides the stomach by electrosonic cutting coagulation device (Thunderbeat, Olympus Co., Japan). A 54-F bougie was placed into the gastric lumen and guided through the pylorus. Depending on the anatomical situation, a two-layer threefold 2/0 polydioxanone (Polydox, Chirana, Czech Republic) running suture was made from fundus to antrum or a $2 / 0$ polydioxanone (Polydox, Chirana, Czech Republic) running suture was made from fundus (one-layer onefold) through the corpus (two-layer threefold) to the antrum (one-layer onefold). The line was knotted by hand with laparoscopic manipulators. The bougie was changed to a common nasogastric tube. Standard cholecystectomy was performed. The posterior wall of the duodenum was dissected from the pancreas to the line of the gastroduodenal artery. The duodenum was dissected 3-4 $\mathrm{cm}$ after the pylorus by cutting-closing laparoscopic tri-stapler (EndoGIA 60, Covidien, Ireland). Viability of the duodenal stump was preserved. The omentum majus was dissected vertically. The ileum (measured $300 \mathrm{~cm}$ back from the ileocaecal junction orally) was positioned tension-free antecolic and tied to the posterior wall of the duodenal stump by $2 / 0$ polyglactin sutures (Surgicryl, SMI AG, Belgium). The proximal duodenal staple line was excised and a lengthwise ileotomy was made. A running hand-sewn end-to-side duodeno-ileostomy was prepared by a $2 / 0$ polydioxanone barbed suture (V-Loc, Covidien, Ireland) and the line was secured by Ligamaxx clips (Ethicon Inc., USA) if necessary. Air-water proofing was performed. The oral part of the sewn ileum was connected to the stomach by $2 / 0$ polyglactin sutures (Surgicryl, SMI AG, Belgium) to protect the anastomosis and reduce alkaline reflux. Intra-abdominal drainage was placed through the right upper abdominal port. The cholecyst was removed from the abdomen. During trocar removal, abdominal wall sanguinations were visualised. After exsufflation, the skin wounds were closed. A short video report is available at online depository.

\section{Perioperative period}

Patients routinely spent the first $36-48 \mathrm{~h}$ after operation in ICU. On the first postoperative day, a swallowing X-ray was performed with gastrografin (Bayer Pharma AG, Germany). If there was no leak, the nasogastric tube would be removed. Patients were advised to drink by gulps, up to $200 \mathrm{ml}$ on the first postoperative day, $500 \mathrm{ml}$ on the second postoperative day and so on, finally reaching $2000 \mathrm{ml}$. Routinely, 6000NE enoxaparin (Clexane, Sanofi, France) injections were administered during the first month. Compression I elastic graduated stockings were applied perioperatively. Analgesics and antiemetics were part of routine treatment. Patients were advised to take oral vitamins (some kind of complex product containing types of vitamin B and D), iron supplementation (combination of $100 \mathrm{mg}$ ferric (III) hydroxide polymaltose and $0.35 \mathrm{mg}$ folic acid two times daily) and oral PPI (pantoprazole $40 \mathrm{mg}$ one time daily) during the first postoperative month. In case of malabsorption, vitamin and iron supplementation was prolonged until serum levels were normalised or clinical signs were diminished. PPI intake was also continued in case of persistent symptoms of GERD. The postoperative diet was adapted to the change in upper gastrointestinal tract anatomy. Nutrition was set up depending on consistency of the meal during the first 8 weeks. Appropriate fluid (1500-2000 ml distributed in $200-300 \mathrm{ml}$ portions per hour) and protein intake were emphasised. Initially, daily calorie intake was advised to be kept at 900-1000 kcal (protein: $73 \mathrm{~g}$, carbohydrate: $73 \mathrm{~g}$, fat: $43 \mathrm{~g}$ ) which was raised to $1200 \mathrm{kcal}$ (protein: $87 \mathrm{~g}$, carbohydrate: $87 \mathrm{~g}$, fat: $51.6 \mathrm{~g}$ ) and $1500 \mathrm{kcal}$ (protein: $109 \mathrm{~g}$, carbohydrate: $109 \mathrm{~g}$, fat: $64.5 \mathrm{~g}$ ) for women and men, respectively, after the third week. Later, patients were advised to 
keep to a standardised diet containing equal quantities of carbohydrate and protein (30-30\%) and 40\% fat (1200 kcal for women, $1500 \mathrm{kcal}$ for men). No added sugar was permitted. During the first 1-3 weeks, fat intake was calculated from the natural content of dishes. Afterward, the daily addition of 5-10 g of fat to food was advised. Five meals were taken every day. If necessary, meal replacements (Fresubin Protein Energy Drink, Fresenius Kabi, Ireland) or protein additives (Protifar, Nutricia, Netherlands) were permitted to complete the suggested carbohydrate, protein and fat intake. Appropriate replacement of vitamins and trace elements was necessary. After the first 8 weeks, patients were advised to keep to a balanced weight-loss diet containing equal quantities of carbohydrate, protein and fat to maintain a negative energy balance providing a deficit of 500-1000 kcal daily. The calorie requirement of each patient was calculated by Millfin St. Jeor BMR estimation formula corrected for age, gender, height, weight and activity level. Adequate weekly physical activity was advocated.

\section{Study size}

The sample size was calculated statistically to reduce skewness. Considering a normal distribution with a statistical power of $80 \%$ and a type I error of 5\%, the sample size was calculated to be 32 patients. Considering a 10\% dropout rate, 35 cases were planned for inclusion in the study.

\section{Statistical analysis}

Variables with normal distribution (analysed by Kolmogorov-Smirnov and Shapiro-Wilk tests) were presented by mean and SD; non-normally distributed variables were expressed by median and interquartile range. Categorical variables were presented as number and percentage. Means of continuous normally distributed records were analysed by two-sample $t$-test or ANOVA. The $p$-value was set to 0.05 .

\section{Results}

\section{Participants}

During enrolment, 26 patients were scheduled for surgery; nine of them were excluded from the trial for different reasons, leaving 17 cases for final evaluation ( 15 females, mean age of included patients 40 years). Details are shown in the flow diagram (Fig. 1).

\section{Descriptive data}

All surgeries were performed laparoscopically. On average, it took $205 \mathrm{~min}$ to perform SADI-GP. After 10 operations, procedures became faster. In two cases, cholecystectomy was performed earlier, but one of them had an uncomplicated Meckel diverticulum that was also resected during surgery. Only two patients had verified stones in the gallbladder before surgery, but pathological examination showed chronic inflammation in all specimens and cholesterolosis (non-neoplastic polyps) in 6 of 15 cases. Patients were observed on average for $42 \mathrm{~h}$ in the ICU and spent 7 days in hospital. Comorbid conditions related to obesity were frequent; the characteristics of the cases are presented in Table 1. Obesity-related comorbidities had shown favourable resolution rates (hypertension: $33 \%, 44.4 \%, 77.8 \%$ and $77.8 \%$, dyslipidaemia: $36.4 \%, 36.4 \%, 72.7 \%$ and $81.2 \%$, prediabetes and diabetes: $54.5 \%, 81.8 \%, 81.8 \%$ and $100 \%$ at 1-, 3-, 6- and 12-month follow-ups, respectively). Symptomatic GERD was frequent. Five patients presented gastritis at baseline, all of them were cured before surgery and there was no relapse observed during follow-up. NAFLD was present at a high rate (94.1\%). In the first month, more patients presented higher levels of liver enzymes, which fell at 3and 6-month follow-ups and remained stable. High levels of uric acid were presented by $52.9 \%$ of cases at baseline, decreasing to $41.2 \%, 35.3 \%, 25 \%$ and $7.1 \%$ at 1-, 3-, 6- and 12-month follow-ups, respectively.

\section{Primary outcomes}

There was no conversion, death, bleeding, VTE or 30-day readmission to hospital after the surgeries. The overall perioperative complication rate was high $(29.4 \%)$. There were two severe complications (11.8\%). We experienced a CD4a (pulmonary insufficiency due to chronic lung disease) and a CD3b (anastomosis leakage treated laparoscopically by stitches) complication. Vomiting occurred in three cases (CD1) which represents $17.6 \%$ of patients with mild perioperative complication rate. We did not experience gastric wall prolapse or release after surgeries. All operated stomachs showed a cone shape around the cardia on the postoperative swallowing X-ray. Among late side effects, there were no clinical signs of bile reflux or narrowing of duodeno-ileal anastomosis. Mild anaemia (treated by iron supplementation) was frequent $(7.1 \%, 33.3 \%$ and $38.5 \%$ at 3,6 and 12 months of follow-up, respectively) in an increasing pattern of incidence but hypoproteinaemia (16.7\% and $15.4 \%$ at 6 and 12 months of follow-up, respectively) was rare. Overall nutrient deficiency $(17.6 \%, 35.7 \%, 66.7 \%$ and $23.1 \%$ at $1,3,6$ and 12 months of follow-up, respectively), diarrhoea $(52.9 \%, 41.2 \%, 52.9 \%$ and $23.5 \%$ at $1,3,6$ and 12 months of follow-up, respectively) and hair loss (47.1\%, $47.1 \%$ and $17.6 \%$ at 3,6 and 12 months of follow-up, respectively) were frequent during the first 6 months after surgery, but the occurrence of these late side effects decreased remarkably by the end of the first year. Detailed results are listed in Table 2. 
Fig. 1 Flow chart of the study

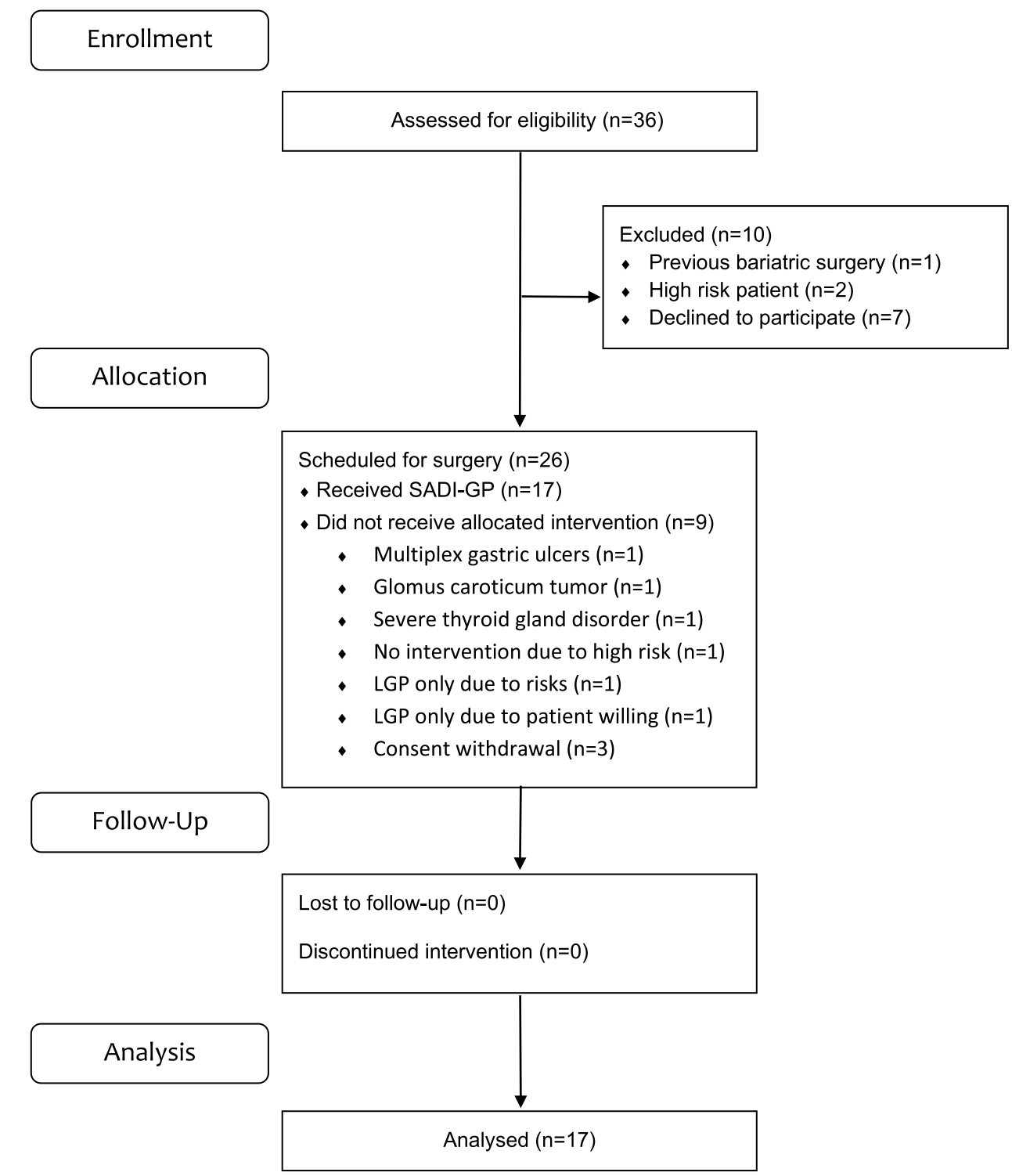

\section{Secondary outcomes}

Weight-loss outcomes were very favourable representing significant improvement (two-sample $t$-test, $p<0.001$ for all variables at 1 year) in weight loss and decrease in BMI respectively. Patients presented a mean bodyweight of $142.54 \mathrm{~kg}$ (mean BMI: 50.21) at baseline, which decreased to $83.96 \mathrm{~kg}$ (mean BMI: 29.58) at 12-month follow-up, resulting in a mean loss of $24.71 \%, 38.91 \%$ and $53.20 \%$ of overweight and $11.62 \%, 18.54 \%, 26.46 \%$ and $35.58 \%$ of total bodyweight at the respective follow-up timepoints. After favourable initial (at the 1- and 3-month follow-ups) results, a 37-year-old female patient presented weight regain and worsened thyroid hypofunction; however, her metabolic parameters remained within an acceptable range. Psychological assessment by using Individual Focused Cognitive Behavioral Therapy (PF-CBT) via video call revealed chronic overeating tendencies since childhood deriving from instrumental intrafamilial physical abuse and school bullying. Such unresolved traumatic events along with social isolation due to the COVID-19 pandemic and householdchore-related stress factors overloaded the subject's coping abilities, leading to excess calorie intake. Another female patient (47 years old) regained weight (10 kg of the $34 \mathrm{~kg}$ lost) between the 6- and 12-month follow-ups. The reasons were disturbed microsocial circumstances, chronic diseaserelated care burden on the patient and foster care of the patient's grandchild due to drug-related criminal charges against the patient's offspring. Due to the aforementioned reasons, slow but steady loss of control over eating habits was detected and interventional PF-CBT was commenced by the second author in order to reverse the weight gain.

There was no weight regain observed among the remaining patients. Most of them experienced satisfactory 


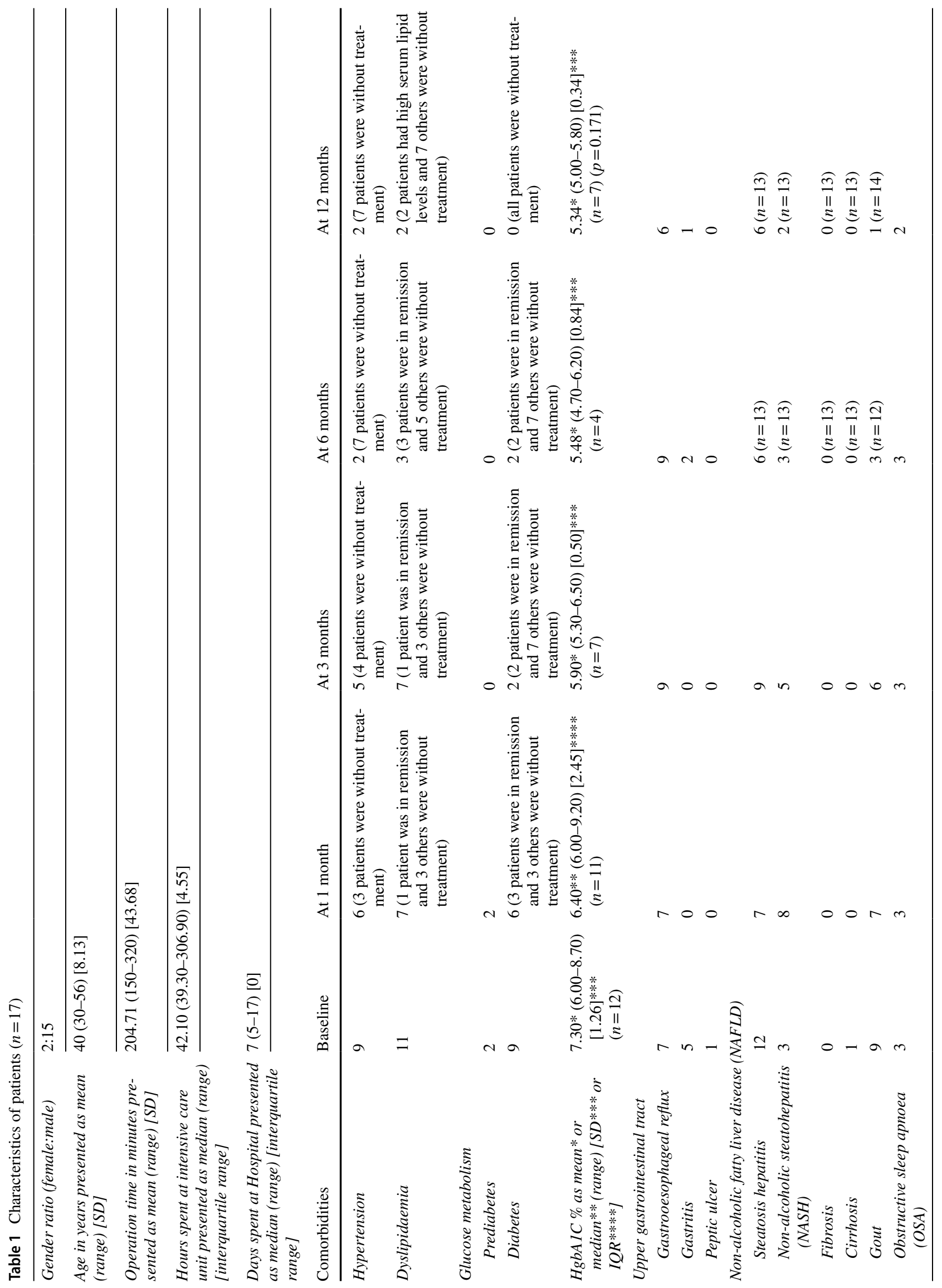




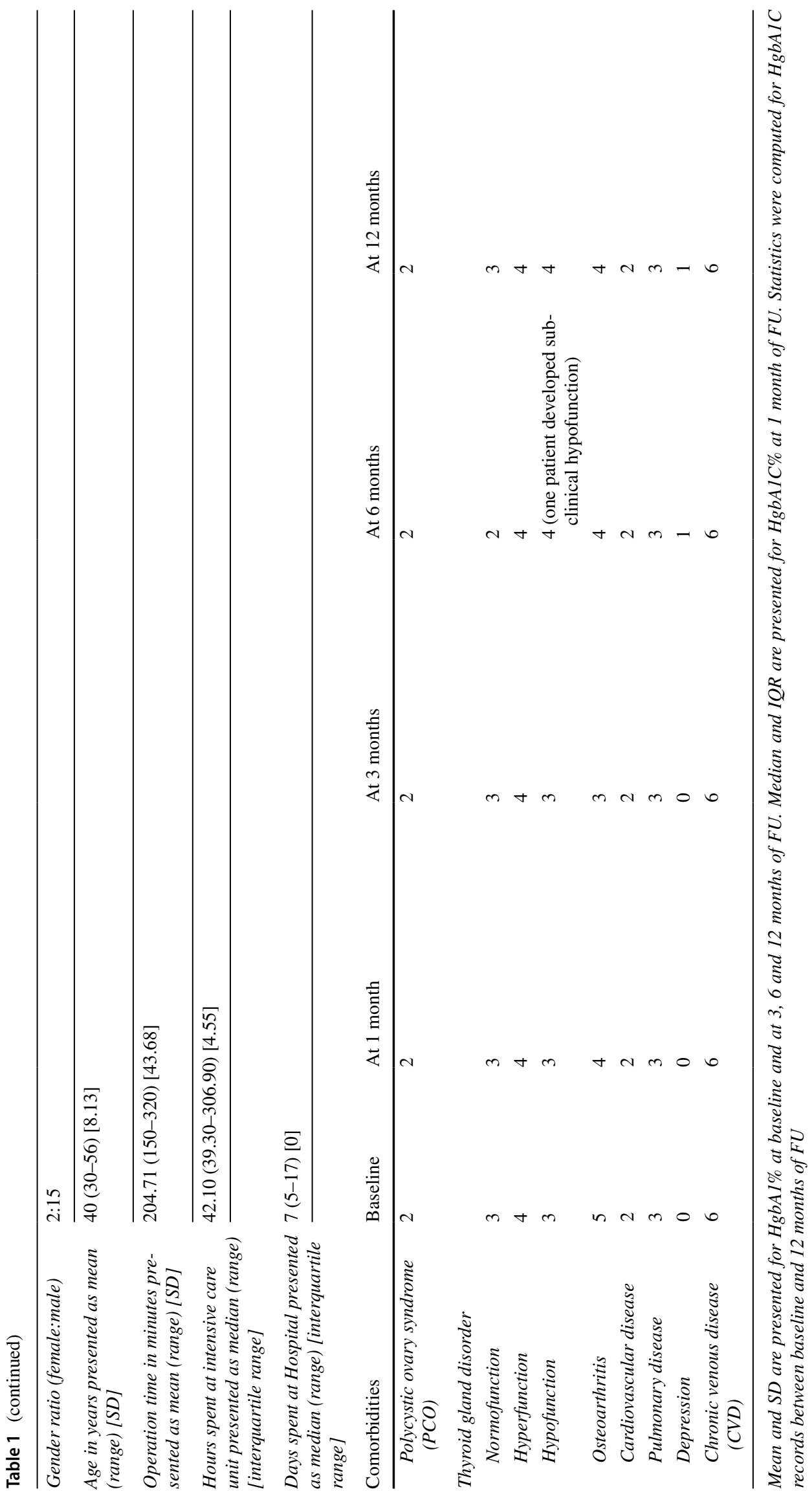


Table 2 Primary outcomes $(n=17)$

Perioperative complications

Leakage

Anastomosis

1 (CD3b, treated laparoscopically by stitches)

Duodenal stump

Stenosis of the duodeno-ileal anastomosis

Bleeding

Wound healing disorder

Cardiovascular

Pulmonary

Vomiting

Gastric wall prolapse

30-day hospital readmission

Complications classified according to Clavien-Dindo

$\begin{array}{ll}1 & 3 \\ 2 & 0 \\ 3 a & 0 \\ 3 b & 0 \\ 4 a & 1 \\ 4 b & 1 \\ 5 & 0 \\ & \end{array}$

Late side effects

Bile reflux

Stenosis of duodeno-ileal anastomosis

Anaemia

Overall nutrient deficiency

Low serum level of iron

Low serum level of magnesium

Low serum level of calcium

Low serum level of vitamin $D$

Hypoproteinaemia

Diarrhoea

Hair loss

\begin{tabular}{llll} 
At 1 month & At 3 month & At 6 month & At 12 months \\
0 & 0 & 0 & 0 \\
0 & 0 & 0 & 0 \\
0 & $1(n=14)$ & $4(n=12)$ & $5(n=13)$ \\
3 & $5(n=14)$ & $8(n=12)$ & $3(n=13)$ \\
3 & 3 & 6 & 2 \\
0 & 1 & 0 & 0 \\
0 & 1 & 1 & 0 \\
0 & 1 & 2 & 1 \\
0 & $0(n=14)$ & $2(n=12)$ & $2(n=13)$ \\
9 & 7 & 9 & 4 \\
0 & 8 & 8 & 3 \\
\hline
\end{tabular}

weight-loss outcomes ( $88.2 \%$ had an EWL\% over $45 \%$ ). Patient's QoL improved significantly along with the weight loss. The Weiner et al. questionnaire showed a mild amelioration (two-sample $t$-test, $p=0.003$ at 1 year), contrary to the BAROS-Moorehead-Ardelt II questionnaire, which represented remarkable improvement (two-sample $t$-test, $p<0.001$ at 1 year). Detailed results are listed in Table 3 .

\section{MMPI-2 results}

Patients were grouped based on the physiological parameter of percentage total weight loss (based on 12-month results) into the groups of those with values below 30 (TWL-30b) and above 30 (TWL-30a) and their data on the Clinical Scales, Revised Clinical Scales, Supplemental Scales, Content Scales and PSY-5 Scales compared. Independent sample $t$-tests were applied to identify any differences, which was appropriate because scores fell into the normal and high ranges on most subscales. Low scores appeared only for one subscale (High/Low scores on Cynicism); the result for this subscale is discussed separately. Based on the test scores on the physiological parameter of percentage total weight loss (based on 12-month results), five patients were included in the TWL-30b group (all participants were females; age 


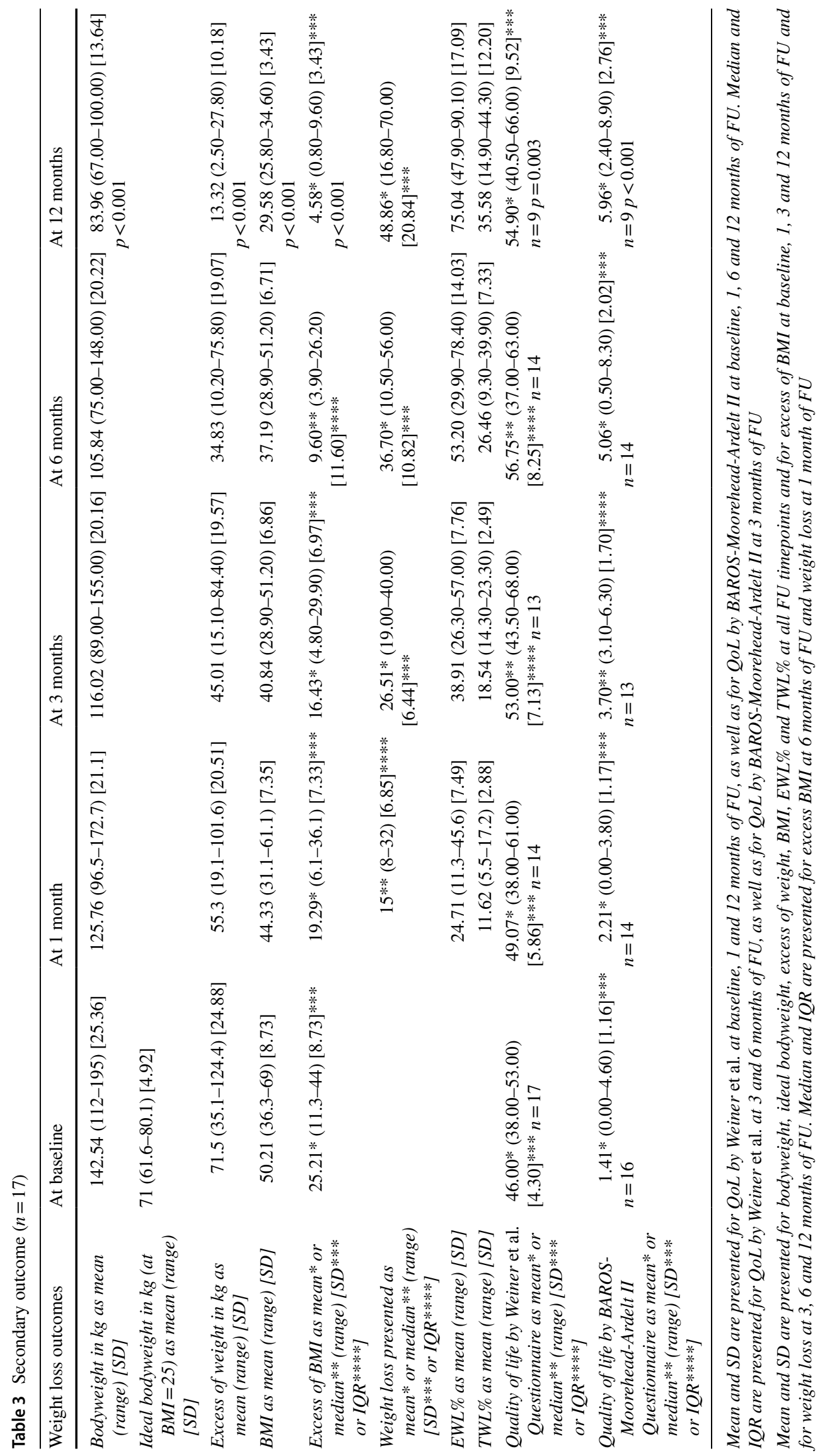


$\mathrm{M}=44.2 ; \mathrm{SD}=8.90)$ and 11 patients in the TWL-30a group ( 2 males/ 9 females; age $\mathrm{M}=39.09 ; \mathrm{SD}=5.96$ ). Along the Clinical Scales, a difference was found on Depression (D; $t(13.958)=-2.373 ; p=0.00 ; p<0.05)$; participants in the TWL-30a group tended to show a higher score on this subscale $(\mathrm{M}=57.90 ; \mathrm{SD}=11.57)$ than those in the TWL-30b group $(M=45.00 ; S D=4.64)$. In the other subscales of the Clinical Scales there were no differences between the groups (see Suppl.1). On the Revised Clinical Scales, a significant group difference was found for Low Positive Emotions (Rc2; $t(13.301)=-2.954 ; p=0.00 ; p<0.05)$; participants in the TWL-30a group showed higher scores on this subscale $(\mathrm{M}=59.09 ; \mathrm{SD}=14.33)$ than those in the TWL-30b group $(M=39.40 ; \mathrm{SD}=4.56)$. Along the other subscales of the Revised Clinical Scales, there were no differences between the groups (see Suppl. 2). On the High/Low Scores on Cynicism (Rc3) subscale, patients showed both high and low scores, so we compared the groups using a $2 \times 2$ ANOVA (percentage total weight loss $\times$ High/Low Cynicism), and there was no statistically significant difference between the groups $(F(1)=1.156 ; p=0.30)$, but there was no participant in the TWL-30b group with a low score for Cynicism (see Suppl. 3). Along the Supplemental Scales, we did not find any significant group differences (see Suppl. 4), nor along the Content Scales (see Suppl. 5). Along the PSY-5 Scales, we saw a significant difference on Introversion/Low Positive Emotionality $($ INTR/LPE; $t(13.408)=-1.914$; $p=0.02 ; p<0.05)$, which appeared higher in the TWL-30a group $(\mathrm{M}=57.45 ; \mathrm{SD}=15.77)$ than in the TWL-30b group $(M=43.40 ; S D=5.18)$. Along the other subscales of the PSY-5 Scales, there were no differences between the groups (see Suppl. 6). Based on 12-month BMI values, patients could be categorised into subgroups of $<35$ (BMI-35b), 35-40 (BMI-35-40) and > 40 (BMI-40a), and we compared their data on the Clinical Scales, Revised Clinical Scales, Supplemental Scales, Content Scales and PSY-5 Scales with One-Way ANOVA (for the three groups). Based on the BMI (based on 12-month results), 10 patients were included in the BMI-35b group ( 1 male/ 9 females; age $M=39.30$; $\mathrm{SD}=5.72)$; two in the BMI-35-40 (1 male/1 female; age $\mathrm{M}=38.50 ; \mathrm{SD}=7.78$ ) and four in the BMI-40a group (all were females; age $\mathrm{M}=45.25$; $\mathrm{SD}=9.91$ ). However, it should not be overlooked that the three groups were of different sizes, so the results can only be interpreted broadly. Along the Clinical Scales, there was no difference between the groups (see Suppl.7). On the Revised Clinical Scales, significant group difference was found on Low Positive Emotions $(\operatorname{Rc} 2 ; F(2)=4.037 ; p=0.04 ; p<0.05)$; participants in the BMI-35-40 group show the highest scores on this subscale $(\mathrm{M}=68.00 ; \mathrm{SD}=8.48)$, followed by the BMI-35b group $(\mathrm{M}=55.60 ; \mathrm{SD}=14.89)$, and the BMI-40a group showed the lowest scores $(\mathrm{M}=38.75 ; \mathrm{SD}=4.99)$. We also found a significant differences between the groups on Aberrant
Experiences $(\mathrm{Rc} 8 ; F(2)=4.674 ; p=0.03 ; p<0.05)$, participants in the BMI-40a group show the highest scores $(\mathrm{M}=58.75 ; \mathrm{SD}=16.07)$, followed by the BMI-35-40 group $(\mathrm{M}=50.50 ; \mathrm{SD}=2.12)$, and the BMI-35b group showed the lowest scores $(\mathrm{M}=43.30 ; \mathrm{SD}=4.57)$. Along the other subscales of the Revised Clinical Scales, there were no differences between the groups (see Suppl. 8). On the High/Low Scores on the Cynicism (Rc3) subscale, patients showed both high and low scores, so we compared the groups using a $2 \times 2$ ANOVA (BMI $\times$ High/Low Cynicism), and there was no statistically significant difference between the groups $(F(2)=0.393 ; p=0.67)$, but only some participants in the BMI-35b group had low scores on this subscale, and none in the other two groups (see Suppl. 9). Along the Supplemental Scales, we did not find any significant group differences (see Suppl. 10), nor along the Content Scales (see Suppl. 11). Along the PSY-5 Scales, we found no significant group differences (see Suppl. 12). We were able to group patients based on weight loss into the groups that lost at least $50 \mathrm{~kg}$ in a year (WL-50a) and who lost less than $50 \mathrm{~kg}$ (WL-50b) and compared their data on the Clinical Scales, Revised Clinical Scales, Supplemental Scales, Content Scales and PSY-5 Scales. Independent samples $t$-tests were applied to identify any differences, which was appropriate because scores fell into the normal and high ranges for most subscales. Low scores appeared only for one subscale (High/ Low scores on Cynicism); the result along this subscale is discussed separately. Based on the test scores on weight loss, eight patients were included in the WL-50b group ( 1 male/7 females; age $\mathrm{M}=42.50 ; \mathrm{SD}=8.65$ ) and eight in the WL-50a group ( 1 male/7 females; age $\mathrm{M}=38.87$; $\mathrm{SD}=5.14$ ). Along the Clinical Scales, we did not find any significant group differences (see Suppl. 13), nor on the Revised Clinical Scales (see Suppl. 14). On the High/Low Scores on Cynicism (Rc3) subscale, patients showed both high and low scores, so we compared the groups using a $2 \times 2$ ANOVA (weight loss $\times$ High/Low Cynicism), and there was no statistically significant difference between the groups $(F(1)=0.136 ; p=0.72)$, but there was no participant in the WL-50b group with a low score on Cynicism (see Suppl. 15). Along the Supplemental Scales, we did not find any significant group differences (see Suppl. 16), nor along the Content Scales (see Suppl. 17). Along the PSY-5 Scales, we did not see a significant difference (see Suppl. 18). We examined the psychological characteristics of those who lost at least $50 \mathrm{~kg}$ (WL-50a) in a year by Pearson correlation (IBM SPSS). This physiological parameter showed positive correlations with Ideas of Persecution (Rc6; $r=0.860$; $p=0.00 ; p<0.05$ ); with Bizarre Mentation (BIZ; $r=0.810$; $p=0.01 ; p<0.05$ ); with Self-Deprecation (DEP3; $r=0.714$; $p=0.04 ; p<0.05$ ); with Schizotypal Characteristics (BIZ2; $r=0.848 ; p=0.00 ; p<0.05)$; with Explosive Behaviour (ANG1; $r=0.708 ; p=0.04 ; p<0.05$ ); with Brooding (D5; 
$r=0.727 ; p=0.04 ; p<0.05)$; with Authority Problems ( $\mathrm{Pd} 2$; $r=0.841 ; p=0.00 ; p<0.05)$; with Social Alienation (Pd4; $r=0.845 ; p=0.00 ; p<0.05)$; with Persecutory Ideas (Pa1; $r=0.826 ; p=0.01 ; p<0.05)$; with Social Alienation (Sc1; $r=0.748 ; p=0.03 ; p<0.05$ ); and with Ego Inflation (Ma4; $r=0.785 ; p=0.02 ; p<0.05)$. The weight-loss parameter also showed negative correlations with Femininity/Masculinity (Mf; $r=-0.716 ; p=0.04 ; p<0.05$ ); with Social Responsibility (Re; $r=-0.798 ; p=0.01 ; p<0.05)$; and with Gender Role-Feminine Scale (GF; $r=-0.817 ; p=0.00 ; p<0.05$; see Suppl. 19).

\section{Risk of bias}

Sample size is smaller than expected which could lead to insecure parameters affecting complication rates and late side effects primarily. Weight loss outcomes could be biased by low number of allocated interventions at some timepoints, but 1-year records seem to be representative. MMPI-2 testing was performed only at 1-year follow-up, therefore, the results are only referential. There was no comparator to SADI-GP, thus, all of our observations are only descriptive.

\section{Discussion}

\section{Key results}

Our study showed that SADI-GP is a promising method but there are some concerns. We experienced only one complication related to surgery, which was treated laparoscopically. Late side effects of duodeno-jejunal exclusion were over an acceptable range. Our patients presented favourable weightloss outcomes; in parallel, comorbid conditions related to obesity and QoL improved as expected. MMPI-2 tests showed that subjects with a weight loss of $>30 \mathrm{~kg}$ tended to show higher scores on the Depression (D) and Low Positive Emotions (Rc2) scales, which was supported by higher scores on Introversion/Low Positive Emotionality (INTR/ LPE) scale. When compared by BMI measured at 12-month follow-up, participants in the BMI 35-40 interval group showed the highest scores on the Low Positive Emotions (Rc2) scale compared to those with $\mathrm{BMI} \leq 35$ or $\mathrm{BMI}>40$. A significant difference was found regarding the Aberrant Experiences (Rc8) scale, where participants in the BMI $>40$ group showed the highest scores. A minimum weight loss of $50 \mathrm{~kg}$ over a year had positive correlations with the Ideas of Persecution (Rc6), Bizarre Mentation (BIZ), Self-Deprecation (DEP3), Schizotypal Characteristics (BIZ2), Explosive Behaviour (ANG1), Brooding (D5), Authority Problems (Pd2), Social Alienation (Pd4), Persecutory Ideas (Pa1), Social Alienation (Sc1) and Ego Inflation (Ma4) scales and negative correlations with Femininity/Masculinity (Mf), Social Responsibility (Re) and Gender Role-Feminine (GF) scales.

\section{Limitations}

In general, our study has limitations due to the small sample size and study design. We did not reach the projected number of included cases because we experienced a higherthan-expected dropout rate, and the number of patients with obesity applied for screening was too low considering the strict selection criteria. There is a huge selection bias in this cohort because $88 \%$ of the study population is female. It could skew our results that there was no control endoscopic or radiologic examination scheduled for gastric plicated patients. Routine cholecystectomy was performed in 15 cases which could bias operating time and occurrence of some complications. This paper presents only short-term results; therefore, the efficacy of the procedure cannot be determined this time. Psychological evaluation lacked longitudinal data sources for comparison.

\section{Interpretation}

LGP is not a widely applied restrictive procedure due to the necessity for expert skills in laparoscopic hand sutures and controversial results in the past [9-24]. In case series, favourable complication rates and weight-loss outcomes were observed $[9-14,17]$. On the other hand, non-randomised comparative trials (most of them reporting shortterm results) suggest that LGP is inferior to LSG in terms of efficacy $[15,16,19,21,22]$ except for the RCT of Talebpour et al., because they found an initial significant difference in weight loss between the groups in favour of LSG, but this was equalised in the long term [20]. Later, Heidari et al. published a paper reporting a high rate of revisional surgery after LGP due to ineffective weight-loss management [23]. Neagoe et al. performed a comparative trial of LSG and LGP, which confirmed similar levels of safety of the methods, but LSG was superior to LGP in terms of efficacy after a 6-month follow-up. Most of the authors concluded that LGP is comparable to LSG in terms of postoperative complications; however, Albanese et al. experienced a high revision rate $(60 \%)$ of LGP due to gastric wall prolapse [18]. To our knowledge, there are two meta-analyses and one systematic review available; each of them confirmed the superiority of LSG over LGP in terms of postoperative complications and weight-loss outcomes [51-53]. However, El Soueidy et al. regarded LGP as an acceptable low-budget treatment modality for obesity [54].

For a decade now, laparoscopic SADI or SADJ combined with LSG (regarded as simplified DS) has earned increasing popularity among bariatric surgeons due to its favourable 
complication rates and weight-loss outcomes. Sanchez-Pernaute et al. reported promising results on excellent weightloss outcomes and favourable complication rates [28]. The key question is this: how long a biliopancreatic limb should be planned? Some authors measure the whole length of the small intestine, and afferent limb longitude is determined depending on BMI and comorbidities [39, 55]. OAGB is performed by a short 150-200-cm biliopancreatic limb [36, $37,41,55]$, similarly to SADJ [27]. Others suggest taking the common limb at least $300-\mathrm{cm}$ distant from the ileocecal valve to avoid hypoproteinaemia and anaemia [28, 30, 34]. High-volume studies reporting on consecutive patients regarded SADI-SG as safe and efficient [28, 30-32, 34, 35]. Schoar et al. concluded in their meta-analysis that SADI-SG is a promising bariatric procedure regarding weight-loss outcomes, but it should be standardised due to current technical variability [29]. A meta-analysis by Lee et al., including only cohort studies, concluded that SADI-SG among BPD-DS and LRYGB is efficient as a revisional procedure after LSG [33]. There are major concerns of loop bypass, especially for OAGB, bile reflux through gastro-jejunal or -ileal anastomosis resulting in marginal ulcers and, in the worst case, oesophageal reflux leading to Barret's metaplasia [55-57]; this is in contrast to SADI-SG and SADJ-SG, where it is reported rarely [27, 28, 30-32,34] and results from preservation of the pylorus (functional barrier), which prevents bile reflux in physiological conditions [26].

Elbanna et al. [45] and Mohammed and Aldaaod [46] introduced laparoscopic gastro-ileal bypass with gastric plication (Mohammed and Aldaaod added pyloric plication to the method) which is similar to but not identical with our SADI-GP, because the physiological barrier of the pylorus is ceased; therefore, bile reflux to the stomach, resulting in high rates of anastomotic ulcers, should be expected. However, each short-term study reported the absence of serious biliary symptoms. There were no anastomotic ulcers observed by Elbanna et al. (sample size of 56), but it should be mentioned that Mohammed and Aldaaod experienced anastomotic ulcers in three cases (study population of 270 patients), which were treated conservatively. The studies reported low numbers of complications (two early abdominal collections treated by ultrasound-guided drainage observed by Elbanna et al. and two late perforations treated conservatively by Mohammed and Aldaaod). Side effects such as diarrhoea, anaemia and nutrient deficiencies were infrequent $[45,46]$. Hair loss was described in $53 \%$ of patients treated by Mohammed and Aldaaod [46]. The trials reported favourable weight loss (EWL\% ranged between 72.5 and $90 \%$ ) and metabolic outcomes [45, 46].

MMPI-2 tests showed that greater weight loss carries a greater probability for depression along with a lesser likelihood of positive emotional experiences; therefore, psychological support during follow-up is necessary to maintain weight loss [58]. As an introverted personality setting is examined with greater weight loss, active psychological intervention is required in order to include and maintain subjects in therapy after the surgical procedure $[59,60]$. As subjects with a BMI of 35-40 score significantly higher on the Low Positive Emotions (Rc2) scale, we experienced that the transition from a BMI of $>40$ towards a BMI of $<35$ carries the risk of such a transition evoking anxiety and fear of the changing body. This idea is supported by the significantly high scores achieved by the aforementioned group on the Aberrant Experiences (Rc8) scale, which indicates the need for active guidance from medical professionals during this transition $[61,62]$.

\section{Comparison with other procedures}

LRYGB had hegemony in bariatric surgery over the last decades. It was challenged by LSG (part of DS) because of simplicity and favourable efficacy. Perioperative mortality rates are proven to be below $0.2 \%$. Overall, serious complications occur in less than $6 \%$ of patients for LSG and $9 \%$ of operated cases for LRYGB, respectively. Short-term reoperation rates should occur below 3\% for LSG and $5 \%$ for LRYGB. The long-term TWL\% of each method is around $20 \%$ [63]. The latest systematic reviews including metaanalysis comparing LYRGB with LSG proved controversial results in terms of efficacy and safety [64-66]. OAGB was described to be effective and safe compared to LYRGB [67, 68]. A meta-analysis comparing pylorus-preserving bariatric surgery to duodeno-jejunal bypass liner (endoscopic treatment modality) regarded surgical procedures (mainly SADI-SG) as safer than comparator. Mortality, reoperation rates, overall complications and severe complications for SADI-SG and SADJ-SG were $0.3 \%, 2.5 \%, 12.4 \%$ and $5.7 \%$, respectively. Overall TWL $\%$ at 1 year was described as $36,9 \%(34,6-39 \%)$ which are comparable or even superior to LRYGB and LSG [69]. Our pilot study on SADI-GP has shown that mortality was zero, and there was no conversion, bleeding, VTE or 30-day readmission to hospital after the surgeries. Overall perioperative complication rate was high (29.4\%). There was only one severe complication related to surgery (5.9\%) similar to more widespread methods (LSG, LRYGB, SADJ-SG and SADI-SG). The $17.6 \%$ of patients needed additional treatment due to mild perioperative complications (vomiting) which was a little over of described for SADJ-SG and SADI-SG. It is suggested to keep the common limb at least $300-\mathrm{cm}$ distant from the ileocecal valve to avoid hypoproteinaemia and anaemia $[28,30,34]$. We followed these instructions; however, late side effects such as mild anaemia, nutrient deficiency, diarrhoea and hair loss as a result of malabsorption occurred frequently during the first 6 months after surgery contrary to expected but the occurrence of these adverse effects decreased remarkably 
by the end of first year. Weight loss outcomes were at least similar to SADI-SG and SADJ-SG and superior to LRYGB and LSG. However, it should be emphasised that the overall results of our small descriptive observational study are not really comparable to complication rates and efficiency of known and widely studied methods due to high risk of bias.

\section{Conclusion}

According to our safety study, SADI-GP is a promising pylorus-preserving malabsorptive procedure, but a longterm high-volume case series or a randomised controlled trial is necessary to evaluate complication rates and weightloss outcomes. Surgical procedures initiate the process of weight loss, but psychological interventions must take over in order to maintain it, due to the widespread changes in the psyche and behaviour of subjects following surgical intervention. The lack of these will decrease the efficacy of weight control in the long term.

Supplementary Information The online version contains supplementary material available at https://doi.org/10.1007/s00423-021-02276-9.

Funding Open access funding provided by Hospital Library of County Zala Saint Rafael. LASAGNE trial (LAparoscopic SingleAnastomosis duodeno-ileal bypass with Gastric plication (SADI-GP) in the maNagEment of morbid obesity) registered under the number of ISRCTN12800723 was funded by Kanizsai Dorottya Hospital (Hospital of Nagykanizsa) and approved by the institutional review board under the protocol number of KDK-2071-2/2019.

\section{Declarations}

Ethics approval All procedures performed in studies involving human participants were in accordance with the ethical standards of the institutional and/or national research committee and with the 1964 Helsinki declaration and its later amendments or comparable ethical standards.

Informed consent Informed consent was obtained from all individual participants included in the study.

Conflict of interest The authors declare no competing interests.

Open Access This article is licensed under a Creative Commons Attribution 4.0 International License, which permits use, sharing, adaptation, distribution and reproduction in any medium or format, as long as you give appropriate credit to the original author(s) and the source, provide a link to the Creative Commons licence, and indicate if changes were made. The images or other third party material in this article are included in the article's Creative Commons licence, unless indicated otherwise in a credit line to the material. If material is not included in the article's Creative Commons licence and your intended use is not permitted by statutory regulation or exceeds the permitted use, you will need to obtain permission directly from the copyright holder. To view a copy of this licence, visit http://creativecommons.org/licenses/by/4.0/.

\section{References}

1. Neeland IJ, Poirier P, Després JP (2018) Cardiovascular and metabolic heterogeneity of obesity: clinical challenges and implications for management. Circulation 137(13):1391-1406. https:// doi.org/10.1161/CIRCULATIONAHA.117.029617

2. Colquitt JL, Pickett K, Loveman E, Frampton GK. Surgery for weight loss in adults. Cochrane Database of Systematic Reviews 2014, Issue 8. Art. No.: CD003641. https://doi.org/10.1002/14651 858.CD003641.pub4

3. Lee WJ, Almulaifi A (2015) Recent advances in bariatric/metabolic surgery: appraisal of clinical evidence. J Biomed Res. 29(2):98-104. https://doi.org/10.7555/JBR.28.20140120

4. Ruban A, Stoenchev K, Ashrafian H, Teare J (2019) Current treatments for obesity. Clin Med (Lond). 19(3):205-212. https:// doi.org/10.7861/clinmedicine.19-3-205

5. Cresci B, Cosentino C, Monami M, Mannucci E. Metabolic surgery for the treatment of type 2 diabetes: a network metaanalysis of randomized controlled trials. Diabetes Obes Metab. 2020 Apr 3. https://doi.org/10.1111/dom.14045. [Epub ahead of print]

6. Carrano FM, Peev MP, Saunders JK, Melis M, Tognoni V, Di Lorenzo N (2020) The role of minimally invasive and endoscopic technologies in morbid obesity treatment: review and critical appraisal of the current clinical practice. Obes Surg 30(2):736752. https://doi.org/10.1007/s11695-019-04302-8.Review

7. Ding L, Fan Y, Li H, Zhang Y, Qi D, Tang S, Cui J, He Q, Zhuo C, Liu M (2020) Comparative effectiveness of bariatric surgeries in patients with obesity and type 2 diabetes mellitus: a network metaanalysis of randomized controlled trials. Obes Rev 21(8):e13030. https://doi.org/10.1111/obr.13030 (Epub 2020 Apr 14)

8. Balint IB, Orban L, Farics A, Manfai G, Radics P (2019) Laparoscopic gastric plication with pylorus preserving duodenoileal bypass for treating morbid obesity. Orv Hetil 160(43):1714-1718

9. Wilkinson LH, Peloso OA (1981 May) Gastric (reservoir) reduction for morbid obesity. Arch Surg 116(5):602-605

10. Talebpour M, Amoli BS (2007) Laparoscopic total gastric vertical plication in morbid obesity. J Laparoendosc Adv Surg Tech A. 17(6):793-8. https://doi.org/10.1089/lap.2006.0128

11. Ramos A, Neto MG, Galvao M et al (2010) Laparoscopic greater curvature plication: Initial results of an alternative restrictive bariatric procedure. Obes Surg 20(7):913-918

12. Brethauer SA, Harris JL, Kroh M et al (2011) Laparoscopic gastric plication for treatment of severe obesity. Surg Obes Relat Dis 7(1):15-22. https://doi.org/10.1016/j.soard.2010.09.023

13. Skrekas G, Antiochos K, Stafyla VK (2011) Laparoscopic gastric greater curvature plication: results and complications in a series of 135 patients. Obes Surg 21(11):1657-1663

14. Niazi M, Maleki AR, Talebpour M (2013) Short-term outcomes of laparoscopic gastric plication in morbidly obese patients: importance of postoperative follow-up. Obes Surg 23(1):87-92

15. Shen D, Ye H, Wang Y et al (2013) Comparison of short-term outcomes between laparoscopic greater curvature plication and laparoscopic sleeve gastrectomy. Surg Endosc 27(8):2768-2774

16. Abdelbaki TN, Sharaan M, Abdel-Baki NA, Katri K (2014) Laparoscopic gastric greater curvature plication versus laparoscopic sleeve gastrectomy: early outcome in 140 patients. Surg Obes Relat Dis. 10(6):1141-6. https://doi.org/10.1016/j.soard.2014. 03.014 (Epub 2014 Mar 28)

17. Kim SB, Kim KK, Chung JW, Kim SM (2015 Oct) Initial experiences of laparoscopic gastric greater curvature plication in Korea-a review of 64 cases. J Laparoendosc Adv Surg Tech A 25(10):793-799. https://doi.org/10.1089/lap.2015.0164 (Epub 2015 Sep 21) 
18. Albanese A, Prevedello L, Verdi D, Nitti D, Vettor R, Foletto M (2015 Sep 1) Laparoscopic gastric plication: an emerging bariatric procedure with high surgical revision rate. Bariatr Surg Pract Patient Care 10(3):93-98 (PMID: 26421246)

19. Chouillard E, Schoucair N, Alsabah S, Alkandari B, Montana L, Dejonghe B, Biagini J (2016 Jun) Laparoscopic gastric plication (LGP) as an alternative to laparoscopic sleeve gastrectomy (LSG) in patients with morbid obesity: a preliminary, short-term, case-control study. Obes Surg 26(6):1167-1172. https://doi.org/ 10.1007/s11695-015-1913-2

20. Talebpour M, Sadid D, Talebpour A, Sharifi A, Davari FV. (2017) Comparison of short-term effectiveness and postoperative complications: laparoscopic gastric plication vs laparoscopic sleeve gastrectomy. Obes Surg. https://doi.org/10.1007/s11695-017-2951-8. [Epub ahead of print]

21. Gudaityte R, Adamonis K, Maleckas A (2018 Dec) Laparoscopic gastric greater curvature plication: intermediate results and factors associated with failure. Obes Surg 28(12):4087-4094. https://doi. org/10.1007/s11695-018-3465-8

22. Li YH, Wang BY, Huang YC, Tsao LC, Chan CP, Huang CY, Chang HC (2019 Feb) Clinical outcomes of laparoscopic greater curvature plication and laparoscopic sleeve gastrectomy: a casematched control study. Obes Surg 29(2):387-393. https://doi.org/ 10.1007/s11695-018-3527-y

23. Heidari R, Talebpour M, Soleyman-Jahi S, Zeinoddini A, Sanjari Moghaddam A, Talebpour A (2019 Feb) Outcomes of reoperation after laparoscopic gastric plication failure. Obes Surg 29(2):376386. https://doi.org/10.1007/s11695-018-3522-3

24. Neagoe RM, Timofte D, Mureşan M, Voidăzan S, Sala D, Borz MB, Borz PC, Ciuntu B, Balan GG, Borz OC (2019) Laparoscopic gastric plication vs laparoscopic sleeve gastrectomy - a single center, prospective and case-control study. Chirurgia (Bucur) 114(6):769-778. https://doi.org/10.21614/chirurgia.114.6.769

25. Scopinaro N, Gianetta E, Civalleri D, Bonalumi U, Bachi V (1979) Bilio-pancreatic bypass for obesity: II. Initial experience in man. Br J Surg 66(9):618-20

26. Marceau P, Biron S, Bourque RA, Potvin M, Hould FS, Simard S (1993 Feb) Biliopancreatic diversion with a new type of gastrectomy. Obes Surg 3(1):29-35

27. Praveen Raj P, Kumaravel R, Chandramaliteeswaran C, Rajpandian S, Palanivelu C (2012 Mar) Is laparoscopic duodenojejunal bypass with sleeve an effective alternative to Roux en $\mathrm{Y}$ gastric bypass in morbidly obese patients: preliminary results of a randomized trial. Obes Surg 22(3):422-426. https://doi.org/10.1007/ s11695-011-0507-x

28. Sánchez-Pernaute A, Rubio MÁ, Cabrerizo L, Ramos-Levi A, Pérez-Aguirre E, Torres A (2015) Single-anastomosis duodenoileal bypass with sleeve gastrectomy (SADI-S) for obese diabetic patients. Surg Obes Relat Dis. 11(5):1092-8. https://doi.org/ 10.1016/j.soard.2015.01.024 (Epub 2015 Feb 7)

29. Shoar S, Poliakin L, Rubenstein R, Saber AA (2018 Jan) Single anastomosis duodeno-ileal switch (SADIS): a systematic review of efficacy and safety. Obes Surg 28(1):104-113. https://doi.org/ 10.1007/s11695-017-2838-8

30. Surve A, Cottam D, Sanchez-Pernaute A, Torres A, Roller J, Kwon Y, Mourot J, Schniederjan B, Neichoy B, Enochs P, Tyner M, Bruce J, Bovard S, Roslin M, Jawad M, Teixeira A, Srikanth M, Free J, Zaveri H, Pilati D, Bull J, Belnap L, Richards C, Medlin W, Moon R, Cottam A, Sabrudin S, Cottam S, Dhorepatil A (2018 May) The incidence of complications associated with loop duodeno-ileostomy after single-anastomosis duodenal switch procedures among 1328 patients: a multicenter experience. Surg Obes Relat Dis 14(5):594-601. https://doi.org/10.1016/j.soard.2018.01. 020 (Epub 2018 Feb 2)

31. Moon RC, Gaskins L, Teixeira AF, Jawad MA (2018 Jun) Safety and effectiveness of single-anastomosis duodenal switch procedure: 2-year result from a single US institution. Obes Surg 28(6):1571-1577. https://doi.org/10.1007/s11695-017-3066-y

32. Zaveri H, Surve A, Cottam D, Cottam A, Medlin W, Richards C, Belnap L, Cottam S, Horsley B (2018 Oct) Mid-term 4-year outcomes with single anastomosis duodenal-ileal bypass with sleeve gastrectomy surgery at a single US center. Obes Surg 28(10):3062-3072. https://doi.org/10.1007/s11695-018-3358-x

33. Lee Y, Ellenbogen Y, Doumouras AG, Gmora S, Anvari M, Hong D (2019 Apr) Single- or double-anastomosis duodenal switch versus Roux-en-Y gastric bypass as a revisional procedure for sleeve gastrectomy: a systematic review and meta-analysis. Surg Obes Relat Dis 15(4):556-566. https://doi.org/10.1016/j.soard.2019.01. 022 (Epub 2019 Jan 31)

34. Surve A, Rao R, Cottam D, Rao A, Ide L, Cottam S, Horsley B (2020 Apr) Early outcomes of primary SADI-S: an Australian experience. Obes Surg 30(4):1429-1436. https://doi.org/10.1007/ s11695-019-04312-6

35. Surve A, Cottam D, Medlin W, Richards C, Belnap L, Horsley B, Cottam S, Cottam A (2020 Nov) Long-term outcomes of primary single-anastomosis duodeno-ileal bypass with sleeve gastrectomy (SADI-S). Surg Obes Relat Dis 16(11):1638-1646. https://doi.org/ 10.1016/j.soard.2020.07.019 (Epub 2020 Jul 31)

36. Rutledge R, Kular K, Manchanda N (2019 Jan) The mini-gastric bypass original technique. Int J Surg 61:38-41. https://doi.org/10. 1016/j.ijsu.2018.10.042 (Epub 2018 Nov 24)

37. Mahawar KK, Parmar C, Graham Y (2019) One anastomosis gastric bypass: key technical features, and prevention and management of procedure-specific complications. Minerva Chir 74(2):126-136. https://doi.org/10.23736/S0026-4733.18.078446 (Epub 2018 Jul 18)

38. Parmar CD, Bryant C, Luque-de-Leon E, Peraglie C, Prasad A, Rheinwalt K, Musella M (2019 Sep) One anastomosis gastric bypass in morbidly obese patients with BMI $\geq 50 \mathrm{~kg} / \mathrm{m} 2$ : a systematic review comparing it with Roux-en-Y gastric bypass and sleeve gastrectomy. Obes Surg 29(9):3039-3046. https://doi.org/ 10.1007/s11695-019-04034-9

39. Kermansaravi M, Pishgahroudsari M, Kabir A, Abdolhosseini MR, Pazouki A (2020) Weight loss after one-anastomosis/minigastric bypass - the impact of biliopancreatic limb: a retrospective cohort study. J Res Med Sci 25:5. https://doi.org/10.4103/jrms. JRMS_117_19 (eCollection 2020)

40. Scavone G, Caltabiano DC, Gulino F, Raciti MV, Giarrizzo A, Biondi A, Piazza L, Scavone A (2020) Laparoscopic mini/one anastomosis gastric bypass: anatomic features, imaging, efficacy and postoperative complications. Updates Surg https://doi.org/10. 1007/s13304-020-00743-4. [Epub ahead of print]

41. Boyle M, Mahawar K (2020 Apr) One anastomosis gastric bypass performed with a $150-\mathrm{cm}$ biliopancreatic limb delivers weight loss outcomes similar to those with a $200-\mathrm{cm}$ biliopancreatic limb at 18-24 months. Obes Surg 30(4):1258-1264. https://doi.org/10. 1007/s11695-019-04359-5

42. Ramos AC, Chevallier JM, Mahawar K, Brown W, Kow L, White KP, Shikora S (2020) IFSO Consensus Conference Contributors. IFSO (International Federation for Surgery of Obesity and Metabolic Disorders) Consensus Conference Statement on OneAnastomosis Gastric Bypass (OAGB-MGB): results of a Modified Delphi Study. Obes Surg 30(5):1625-1634. https://doi.org/ 10.1007/s11695-020-04519-y

43. Karcz WK, Kuesters S, Marjanovic G, Grueneberger JM (2013 Dec) Duodeno-enteral omega switches - more physiological techniques in metabolic surgery. Wideochir Inne Tech Maloinwazyjne 8(4):273-279. https://doi.org/10.5114/wiitm.2013.39647 (Epub 2013 Dec 22)

44. Qiu NC, Li W, Liu ME, Cen XX, Shan CX, Zhang W, Liu Q, Wang Y, Zhu YT, Qiu M (2018 Dec) Comparison of great curvature plication with duodenal-jejunal bypass (GCP-DJB) and sleeve 
gastrectomy (SG) on metabolic indices and gut hormones in type 2 diabetes mellitus rats. Obes Surg 28(12):4014-4021. https://doi. org/10.1007/s11695-018-3459-6

45. Elbanna H, Abdel-Razik MA, Emile SH (2020 Dec) Short-term outcome of single-anastomosis plication ileal bypass (SAPI) in treatment of morbid obesity. Obes Surg 30(12):5041-5046. https://doi.org/10.1007/s11695-020-04961-y (Epub 2020 Sep 10)

46. Mohammed FF, Aldaaod RAA (2016) Single anastomosis gastroileal bypass with pyloric and gastric plication (SAGI PGP): a new innovative bariatric operation. J Gastrointest Dig Syst 6:455. https://doi.org/10.4172/2161-069X.1000455

47. Oria HE, Moorehead MK (2009) Updated bariatric analysis and reporting outcome system (BAROS). Surg Obes Relat Dis. 5(1):60-6. https://doi.org/10.1016/j.soard.2008.10.004 (Epub 2008 Nov 1$)$

48. Weiner S, Sauerland S, Weiner R, Cyzewski M, Brandt J, Neugebauer E (2009) Validation of the adapted Bariatric Quality of Life Index (BQL) in a prospective study in 446 bariatric patients as one-factor model. Obes Facts 2(Suppl 1):63-66. https://doi.org/ 10.1159/000198263 (Epub 2009 Mar 18)

49. Dindo D, Demartines N, Clavien PA (2004 Aug) Classification of surgical complications: a new proposal with evaluation in a cohort of 6336 patients and results of a survey. Ann Surg 240(2):205213. https://doi.org/10.1097/01.sla.0000133083.54934.ae

50. Clavien PA, Barkun J, de Oliveira ML, Vauthey JN, Dindo D, Schulick RD, de Santibañes E, Pekolj J, Slankamenac K, Bassi C, Graf R, Vonlanthen R, Padbury R, Cameron JL, Makuuchi M (2009 Aug) The Clavien-Dindo classification of surgical complications: five-year experience. Ann Surg 250(2):187-196. https:// doi.org/10.1097/SLA.0b013e3181b13ca2

51. Barrichello S, Minata MK, Ruiz García, de Gordejuela A, Bernardo WM, de Souza TF, Galvão Neto M, Hourneaux de Moura DT, Santo MA, Hourneaux de Moura EG (2018) Laparoscopic greater curvature plication and laparoscopic sleeve gastrectomy treatments for obesity: systematic review and meta-analysis of short- and mid-term results. Obes Surg. 28(10):3199-3212. https://doi.org/10.1007/s11695-018-3330-9

52. Perivoliotis K, Sioka E, Katsogridaki G, Zacharoulis D (2018) Laparoscopic gastric plication versus laparoscopic sleeve gastrectomy: an up-to-date systematic review and meta-analysis. J Obes 2018:3617458. https://doi.org/10.1155/2018/3617458.eCollectio n2018

53. Suarez DF, Gangemi A (2021 Jan) How bad is "bad"? A cost consideration and review of laparoscopic gastric plication versus laparoscopic sleeve gastrectomy. Obes Surg 31(1):307-316. https://doi.org/10.1007/s11695-020-05018-w (Epub 2020 Oct 24)

54. El Soueidy T, Kassir R, Nakhoul M, Balian A, Nunziante M, Safieddine M, Perlemuter G, Lainas P, Dagher I (2020) Laparoscopic greater curvature plication for the treatment of obesity: a systematic review. Obes Surg. https://doi.org/10.1007/s11695020-05112-z. Online ahead of print

55. Aleman R, Lo Menzo E, Szomstein S, Rosenthal RJ (2020) Efficiency and risks of one-anastomosis gastric bypass. Ann Transl Med 8(Suppl 1):S7. https://doi.org/10.21037/atm.2020.02.03

56. M'Harzi L, Chevallier JM, Certain A, Autret G, Levenson G, Louis D, Poghosyan T, Berger A, Rahmi G, Broudin C, Clément O, Douard R, Tavitian B, Bruzzi M (2020) Long-term evaluation of biliary reflux on esogastric mucosae after one-anastomosis gastric bypass and esojejunostomy in rats. Obes Surg. https://doi.org/ 10.1007/s11695-020-04521-4. [Epub ahead of print]
57. Saarinen T, Pietiläinen KH, Loimaala A, Ihalainen T, Sammalkorpi H, Penttilä A, Juuti A (2020 Mar) Bile reflux is a common finding in the gastric pouch after one anastomosis gastric bypass. Obes Surg 30(3):875-881. https://doi.org/10.1007/ s11695-019-04353-x

58. Gerber P, Anderin C, Thorell A (2015) Weight loss prior to bariatric surgery: an updated review of the literature. Scand J Surg 104:33

59. Wing RR (2004) Behavioral approaches to the treatment of obesity. In: Bray GA, Bouchard C (eds) Handbook of Obesity: Clinical Applications, 2nd edn. Marcel Dekker, New York

60. Hartmann-Boyce J, Johns DJ, Jebb SA et al (2014) Effect of behavioural techniques and delivery mode on effectiveness of weight management: systematic review, meta-analysis and metaregression. Obes Rev 15:598

61. Teixeira PJ, Carraça EV, Marques MM et al (2015) Successful behavior change in obesity interventions in adults: a systematic review of self-regulation mediators. BMC Med 13:84

62. Wing RR, Tate DF, Gorin AA et al (2006) A self-regulation program for maintenance of weight loss. N Engl J Med 355:1563

63. Arterburn DE, Telem DA, Kushner RF, Courcoulas AP (2020 Sep 1) Benefits and risks of bariatric surgery in adults: a review. JAMA 324(9):879-887. https://doi.org/10.1001/jama.2020.12567

64. Gu L, Huang X, Li S, Mao D, Shen Z, Khadaroo PA, Ng DM, Chen P (2020 Feb 12) A meta-analysis of the medium- and longterm effects of laparoscopic sleeve gastrectomy and laparoscopic Roux-en-Y gastric bypass. BMC Surg 20(1):30. https://doi.org/ 10.1186/s12893-020-00695-x

65. Sharples AJ, Mahawar K (2020 Feb) Systematic review and metaanalysis of randomised controlled trials comparing long-term outcomes of Roux-en-Y gastric bypass and sleeve gastrectomy. Obes Surg 30(2):664-672. https://doi.org/10.1007/s11695-019-04235-2

66. Han Y, Jia Y, Wang H, Cao L, Zhao Y (2020 Apr) Comparative analysis of weight loss and resolution of comorbidities between laparoscopic sleeve gastrectomy and Roux-en-Y gastric bypass: a systematic review and meta-analysis based on 18 studies. Int J Surg 76:101-110. https://doi.org/10.1016/j.ijsu.2020.02.035 (Epub 2020 Mar 6)

67. Lee Y, Doumouras AG, Yu J, Aditya I, Gmora S, Anvari M, Hong D (2019) Laparoscopic sleeve gastrectomy versus laparoscopic Roux-en-Y gastric bypass: a systematic review and meta-analysis of weight loss, comorbidities, and biochemical outcomes from randomized controlled trials. Ann Surg. https://doi.org/10.1097/ SLA.0000000000003671. Online ahead of print

68. Jia D, Tan H, Faramand A, Fang F (2020 Apr) One anastomosis gastric bypass versus Roux-en-Y gastric bypass for obesity: a systematic review and meta-analysis of randomized clinical trials. Obes Surg 30(4):1211-1218. https://doi.org/10.1007/ s11695-019-04288-3

69. Balint IB, Csaszar F, Somodi K, Ternyik L, Biro A, Kaposztas Z (2021) Is duodeno-jejunal bypass liner superior to pylorus preserving bariatric surgery in terms of complications and efficacy? Langenbecks Arch Surg. https://doi.org/10.1007/s00423-02102131-x. Online ahead of print

Publisher's Note Springer Nature remains neutral with regard to jurisdictional claims in published maps and institutional affiliations. 


\title{
Authors and Affiliations
}

\author{
Istvan Bence Balint ${ }^{1} \cdot$ Ferenc Csaszar ${ }^{2,3} \cdot$ Lajos Orban $^{4} \cdot$ Peter Radics $^{5} \cdot$ Akos Farics $^{4} \cdot$ Gergo Manfai $^{4} \cdot$ Veronika Hari $^{6}$. \\ Rebeka Javor ${ }^{7}$ \\ Ferenc Csaszar \\ fjmailnet@gmail.com \\ Lajos Orban \\ lajosorban2@gmail.com \\ Peter Radics \\ drradicspeter@gmail.com \\ Akos Farics \\ faricsakos@gmail.com \\ Gergo Manfai \\ m.gergoe@gmail.com \\ Veronika Hari \\ vera466@gmail.com \\ Rebeka Javor \\ 2 Doctoral School of Neurosciences, University of Pecs, Pécs, \\ Hungary \\ 3 Department of Psychiatric Rehabilitation, Szigetvár Hospital, \\ Szigetvár, Hungary \\ 4 Department of General Surgery, Kanizsai Dorottya Hospital, \\ Nagykanizsa, Hungary \\ 5 Central Anaesthesiological and Intensive Care Unit, Kanizsai \\ Dorottya Hospital, Nagykanizsa, Hungary \\ 6 Department of Nutrition, Kanizsai Dorottya Hospital, \\ Nagykanizsa, Hungary \\ 7 Faculty of Humanities and Social Sciences, Department \\ of Community and Social Studies, University of Pécs, Pécs, \\ Hungary
}

javor.rebeka@pte.hu

Department of General and Vascular Surgery, Zala County Saint Rafael Hospital, Zrínyi Miklós street, 8900 Zalaegerszeg, Hungary 